\title{
Zirconium: The material of the future in modern implantology
}

\author{
Paweł Kubasiewicz-Ross ${ }^{1, B-D}$, Marzena Dominiak, ${ }^{1, \mathrm{~A}, \mathrm{E}}$, Tomasz Gedrange ${ }^{2, A-F}$, Ute U. Botzenhart ${ }^{2, D, E}$ \\ ${ }^{1}$ Department of Oral Surgery, Wroclaw Medical University, Poland \\ ${ }^{2}$ Outpatient Clinic of Orthodontics, Faculty of Medicine Carl Gustav Carus, Dresden, Germany \\ A - research concept and design; $B$ - collection and/or assembly of data; $C$ - data analysis and interpretation; \\ $D$ - writing the article; $E$ - critical revision of the article; $F$ - final approval of article
}

\section{Address for correspondence \\ Paweł Kubasiewicz-Ross \\ E-mail: pawelkubasiewicz@wp.pl}

\section{Funding sources}

None declared

\section{Conflict of interest}

None declared

Received on March 25, 2015

Revised on May 30, 2016

Accepted June 21, 2016

\begin{abstract}
The authors present the contemporary state of knowledge concerning alternative materials for dental implantology. First of all, factors influencing osseointegration are stated. The most important factors seem to be the type of implant surface. Among the numerous parameters describing them, the most important are: average roughness and porous density. Some studies proved that materials with comparable surface roughness provide similar osseointegration. In modern implantology titanium is the material still considered as a "gold standard". However, aesthetic features of titanium still bear several disadvantages, especially in the case of periodontium with a thin biotype in the anterior, aesthetic sensitive area of the jaw. If a titanium implant is used in such a case, the mucosa at the implant's neck may become grayish and, consequently limits the success of the overall treatment. That was the reason for seeking alternative materials to manufacture dental implants. Initiated by general medicine, mainly orthopedics, the search led to the discovery of zirconium dioxide used in dental implantology. A small number of complications, good chemical parameters, anticorrosion, mechanical strength, elasticity module close to the one of steel, and especially biocompatibility made zirconium a perfect material for this purpose, although this material presents several problems in achieving optimal roughness. In this overview one of the probable methods, a process of partial synterization, is presented.
\end{abstract}

Key words: literature review, zirconium, dental implantology

DOI

10.17219/acem/63794

\section{Copyright}

Copyright by Author(s)

This is an article distributed under the terms of the

Creative Commons Attribution Non-Commercial License

(http://creativecommons.org/licenses/by-nc-nd/4.0/) 


\section{Previously used materials in implantology}

People have been trying to recreate lost tooth structures for ages. The first attempts to implant teeth were made as early as in ancient Egypt, and the first "implants" had been animal teeth. Usually, they were made of mechanically shaped parts of ivory. On the basis of other, later excavations, it was claimed that similar implantation procedures were used not only by the ancient Egyptians, but were also found in South America and Europe. The Mayans used volcanic glass, shaped like a tooth root, to achieve immediate implantation of a lost tooth. Also animal shells were used as implant material. ${ }^{1-3}$ The first modern xenogenic material used in implantatology was gold. In 1809 the Italian dentist Maggiolo applied immediately after extraction one-part structures whose root shape matched the tooth socket. ${ }^{4}$ Materials used in implantatology changed over the decades and in the nineteenth century, apart from gold, other metals and materials started to be used: platinum, iridium, lead, rubber and porcelain. In 1934 the Bulgarian surgeon Hans Abel was the first to use an implant made of ferrous alloy. ${ }^{4}$ Three years later Adams was the first to patent two-phase implants, in which, after healing, supra-gingival retaining elements were fixed to the root with the use of a screw. ${ }^{4}$ The first implant that looked like modern implants was created by Strock in 1983, which was made of cobalt-molybdenum alloy. ${ }^{5}$

Nowadays, the most significant metal used in dental implantology is titanium. It became so popular because of it features: biocompatibility, mechanical strength, ability to osseointegrate and the fact that it is easy to produce. The number of recorded treatments with titanium implants combined with long observation periods of them was also important for approving titanium implants as a standard procedure in implantology. ${ }^{6}$ However, the aesthetic features of titanium still bear several disadvantages especially in the case of periodontium with a thin biotype in the anterior, aesthetic sensitive area of the jaw. If a titanium implant is used in such a case, the mucosa in the implant's neck area may become grayish and, consequently, limit the success of the overall treatment. Titanium implants may also require additional surgical procedures concerning soft tissue augmentation, e.g. connective tissue drafting, which aims to widen and thicken calloused gum or bone augmentation due to an age-related bone shift and atrophic and resorptive processes after tooth loss, resultant from a lack of strain, as an important functional stimuli for preservation and remodeling of the alveolar bone. ${ }^{7}$

\section{Materials alternative to titanium}

In order to improve aesthetics, white materials started to be used to produce implants. Due to its good osseo- integrative properties, the first ceramic material used in implantology was aluminum oxide. ${ }^{8,9}$ In follow-up examinations after 10 years, the success of those implants was between 87 and $92.5 \% .^{9,10}$ Systems based on aluminum oxide were used for immediate implantation in cases of single tooth loss in the jaw, in the area of incisors, canines and premolars, i.e. in the areas where chewing forces a relatively weak. Even though implants were used in the above-mentioned clinical circumstances, there were cases of damage caused by chewing functions, and by reason of inadequate mechanical strength, aluminum-oxide implants were no longer in use. ${ }^{11-14}$ Another alternative material was introduced by general medicine, mainly orthopedics. Since the 1970s, zirconium has been used to reconstruct hip joints.

To this day over 1,000,000 treatments using zirconium to replace hip joints have been performed. A small number of complications, good chemical parameters, anticorrosion, mechanical strength, elasticity module close to the one of steel, and especially biocompatibility made zirconium the perfect material for implantology. ${ }^{15,16}$ Zirconium's biocompatibility was thoroughly examined in relations to all cell lines existing in a potential contact with a dental implant. Research conducted by Dion et al. and Li et al. on fibroblast cell lines and epithelial cells, with the use of human cord blood, did not show any cytotoxicity of zirconium. ${ }^{17,18}$ The mentioned researchers added pure zirconium powder after contact and then performed cell proliferation and differentiation with immunofluorescent methods. Ko et al. conducted detailed research on human osteoblast cell lines, in which they compared the population of human osteosarcoma cells on the surfaces of zirconium and pure titanium. ${ }^{19}$ Osteoblast cell lines were incubated on a specially prepared medium, consisting of pure titanium and zirconium. Observations after $6,24,48$ and 96 h were performed with the use of a scanning electron microscope and then cell proliferation was measured as mRNA concentration function with the use of PCR method. The investigation showed the comparative ability of osteoblasts, cultured in contact with both, pure titanium and zirconium, to proliferate and differentiate towards osteocytes. Osteoblasts adhered even better to zirconium surfaces.

\section{The role of implant surface nanostructure in osseointegration}

As far as dental implantology is concerned, the main factor in achieving treatment success is implant osseointegration, i.e. functional incorporation of the implant into the human organism. On microscopic scale, osseointegration appears when there is contact between the implant and the bone (BIC - bone to implant contact).

The main reason why zirconium could not be used as the most common material in dental implantology was 
the fact of its high resistance to physicochemical processes and that its surface cannot be modified to the same extent as titanium surfaces can. Rather than other parameters, e.g. the implant length, the success of osseointegration strongly depends on the implant surface structure, which may be described by many parameters out of which the main 3 are:

a) average roughness $(\mathrm{Ra})$, which is an average measure of values of vertical deviations of a chosen plane from the particular surface points. Mathematically, it is described by the following formula:

$$
\mathrm{R}_{\mathrm{a}}=\frac{1}{L} \int_{0}^{L}[y(x)] d x
$$

where $l$ is a measure of the distance and -function is the value of profile deviations;

b) the distance between particular deviations $(S)$ is mathematically:

$$
\frac{1}{n} \sum_{i=1}^{n} S_{i}, S_{i}=\frac{S_{1}+S_{2}+\ldots+S_{n}}{n}
$$

where $S_{i}$ is a distance between two local peaks and $n$ is the number of distances evaluated on a given distance;

c) porous density (PD). ${ }^{20,21}$

Oshid et al., in their studies, could prove that for optimal osseointegration the Ra parameters of the implant surface have their highest and lowest restrictions. If the roughness is too high ( $\mathrm{Ra}$ below $1 \mu \mathrm{m}$ ) microleakages occur and chemical compounds are released to the external environment. ${ }^{22,23}$ Apart from microleakages, it is stated that excessive roughness of the implant surface represents a mechanical obstacle for culturing the implant surface with cells. Moreover, excessively rough surfaces with too many structural processes of small sizes are surfaces with relatively low integrity. On the other hand, a surface which is too smooth is not an optimal environment to be cultured with osteoblasts. Another problem in this context seems to be the roughness of the transmucosal part of the implant. Due to the fact that the extrinsic fiber cementum on the implant surface is missing, no fiber attachment is possible at the implant neck area, which was why primarily highly polished titanium surfaces were preferred to improve soft tissue attachment in this area, which on the other hand, bears the risk of bone loss and of pronounced epithelial down-growth. ${ }^{24,25}$

In the studies by Matsuzaka et al., it was proved that on a cellular and subcellular level the characteristics of the surface corrugation of the material implanted in the bone tissue influence patterns formed by cells populating this area. ${ }^{26}$ On a rough surface (Ra: $\left.1-2 \mu \mathrm{m}\right)$ osteoblasts were able to fully fill the surface hollows after 8 days of incubation, whereas during the same observation period on a smoother or rougher surface, cell clusters could only be seen at the hollow edges. At a subcellular level, it was proved that increased amounts of endoplasmic reticulum (RE) causes increased metabolic activity of the cells lo- cated in the most internal layers, making the mentioned surface significantly predisposed.

Zinger et al. and Deligianni et al., in their experiments on human osteoblastic sarcoma cell lines, could show that the most preferential diameter of micropores for cell proliferation is $30 \mu \mathrm{m} .{ }^{27,28} \mathrm{With}$ these pore parameters, cells easily adapted to a 3-dimensional medium. Mediums with micropores with diameters of $10 \mu \mathrm{m}$ were not recognized by the cells, whereas in bigger micropores $(100 \mu \mathrm{m})$ cells did not find mechanical retention and were rinsed. These authors also proved the influence of medium size pores on cell differentiation after observing osteoblast filopodia creation.

De Oliveira and Nanci used immunohistochemical methods to prove the increased metabolism of osteoblasts that manifests itself in significantly higher secretion of osteopontin (OPN) and bone sialoproteins (BSP) to extracellular matrix. ${ }^{29}$ It is worth noting that in the mentioned studies there were no statistically significant differences in the synthesis of other protein matrixes: fibronectin, tubulin and type I collagen. However, increased biosynthesis of BSP and OPN was proved, which was a pioneering proof of selective and precise influence of the type of the medium's nanostructure on gene expression, metabolism direction and, as a result, potentially bone tissue cells differentiation. The presence of extracellular matrix, typical for bone tissue, is a factor that differentiates mesenchymal cells towards osteoprogenitor cell lines. Both these processes: primary, resulting from the influence of the medium, and secondary, resulting from the composition of the primary matrix, act additionally in the processes of osteogenesis. Mentioned viewpoints are similar to the results of Delignani et al., who proved the importance of the medium surface to start osteogenesis. ${ }^{28}$ Biological activity and cell adhesion to the medium surface was measured in these studies by checking the alkaline and fibronectin phosphatases activity. According to them, the factor influencing this is the strength of osteoblasts binding to the surface of dental implants.

Anselme and Bigerelle created their own method of evaluating the strength of osteoblast binding to the surface. ${ }^{30}$ After a period of 7, 14, 21 days of incubation, cultured osteoblasts were rinsed with EDTA. The number of cells was counted after 5, 10, 20, 30 and 60 min of centrifuging and measured in a flow cytometer. On the basis of the results, a graph line was created which resembled normal distribution with its maximum around average values (10-30 min). The greater the deviation towards $60 \mathrm{~min}$, i.e. the longer the cells adhered to the medium surface, empirically the stronger was the binding with the medium. The highest results were obtained for the medium of $\mathrm{Ra}=0.76 \mu \mathrm{m}$ and $6.25 \mu \mathrm{m} .{ }^{30}$ On this basis, the term "adhesive power" (AP) was suggested, which is a measure of the deviation from the standard cytometric curve of a normal distribution. 


\section{Osseointegration of zirconium implants}

The topic of the histological evaluation of zirconium implants is still relatively new. The only studies that may be taken into consideration are those in which implant/ bone contact indicator value (BIC) was evaluated, the studies which included a greater number of implants, conducted according to the standards of statistical analyses and those which included the evaluation of titanium implant control group as well. In the current literature there are only a few studies in accordance with these criteria. $^{31-40}$

First, in a time dependent studies about the osseointegration of $\mathrm{n}=156$ zirconium implants with a Ra of $0.9 \mu \mathrm{m}$ the BIC-values (bone-implant contact) reached $86 \%$ after 8 weeks of observation. ${ }^{31}$ However, so far this has been the only study, in which such high BIC-values of osseointegration of zirconium implants were found. In other studies the BIC-values for the above mentioned implants reached 45 and $65 \% .^{32,33}$ In a study of Stanic et al. on 28 zirconium implants with a Ra of $1.26 \mu \mathrm{m}$ the average $\mathrm{BIC}$-value was $56 \%$ after 60 days of observation. ${ }^{34}$ These studies provide unstable results, where the difference between the highest and the lowest BIC-value was about $32 \%$. Scerano et al. as well showed in a rat model that direct bone to zirconium implant contact exists. ${ }^{35}$ In 4-week observations on 20 implants they stated that the BIC-value was $68 \%$. With the same assumptions, Aldini et al. evaluated a BIC of $55 \%( \pm 27 \%)$ after an observation period of 60 days. ${ }^{36}$

Whereas in the last 2 mentioned studies the surface nanostructure features were not taken into consideration, studies of Senerby et al. show quite precise analysis of the relation between the degree of roughness of zirconium implants and the results of osseointegration. ${ }^{37}$ In their study, zirconium implants were divided into 3 groups: the first group included implants with a surface roughness of $0.75 \mu \mathrm{m}$, in the second group the surface roughness was $1.24 \mu \mathrm{m}$, and in the third $0.93 \mu \mathrm{m}$. The research was conducted in a rabbit model where implants were placed in the bone of the tibia and femur. Resultant BIC-values differed depending on the place of implantation. For implants placed in the bone of the femur more referential results were obtained: $46 \%$ for the first group, $60 \%$ for the second and $70 \%$ for the third group, whereas BIC-values for implants placed in the bone of the tibia were much lower: 19, 31 and 22\%, respectively. It may be considered that the most preferential degree of roughness of dental implants made out of zirconium is slightly different from the one of titanium implants.

There are also studies showing much worse osseointegrative features of zirconium implants. In Deprich's study on 48 zirconium implants $(\mathrm{Ra}=0.598 \mu \mathrm{m})$ placed in the tibia of 12 minipigs, the $\mathrm{BIC}$-value reached $18 \%$ after 3 months of observation. ${ }^{38}$ Moreover, it is difficult to dis- cuss the osseointegration of zirconium implants, because not only is the number of studies on this topic small, but they also differ in methodology and consequently in results. For example, osseointegration was evaluated on the basis of observations that included a time span of 2 weeks up to 24 months. Implants were also evaluated on the basis of different animal models and placed in different anatomical structures. Another matter was implant loading. In most studies implants were not loaded, but there are also a few studies in which they had been loaded.

Surprising results were obtained while studying the osseointegration of ceramic implants. Measured BIC-values varied from 2 to $86.8 \% .^{31,32}$ Additionally, not all studies include the evaluation of titanium implants as a control group, which makes it difficult to draw conclusions. Titanium implants, as a reference, were used only in studies conducted by Dubruille et al. and Kohal et al. ${ }^{33,39}$

Based on these studies, it can be concluded that with the osseointegration of zirconium implants the bone tissue behaves the same way without any worse features in comparison to conventionally used titanium implants. Currently, there are only 5 studies comparing the osseointegration of ceramic and titanium implants after loading histologically. ${ }^{37-40}$ The first research with such defined methodology was conducted on a monkey model by Kohal et al. ${ }^{39}$ The investigation period was about 9 months and the implants were loaded after 5 months. In this study, it was proved that osseointegration of ceramic and titanium implants is comparable with an equal BIC of $68 \%$ for ceramic implants.

In other studies, negative behavior of bone tissue in the presence of zirconium implants after loading was observed. ${ }^{40}$ In these cases, immediately loaded zirconium implants (one-phase loading) were used, along with unloaded ones (two-phase loading). Despite generally good BIC-values (around 70\% in all studies), after loading, alveolar marginal bone loss could be detected. Hence, with ceramic implants a 2-phase implantation method seems to be preferable.

In a study by Sennerby et al. that followed these strict criteria, osseointegration of titanium implants and 3 groups of zirconium implants with different types of surface modification were compared. ${ }^{37}$ Osseointegration was evaluated histomorphometrically as well as with the help of SEM imaging and biochemical tests. Referring to these studies, it may be concluded that in the case of zirconium and titanium implants with the same or comparable roughness, the obtained osseointegration is comparably good. In the case of zirconium implants, the method of modifying the surface to obtain such characteristics is a challenge. Methods known for titanium implant surface modification (e.g. acid-etching and sand-blasting) are not successful in the case of zirconium implants, because of the physicochemical parameters of that material.

It seems that it is worth seeking methods to modify zirconium implants surfaces in such a way that they would 
have features and characteristics of ceramic material surfaces. One of the probable methods is a process of partial synterization, in which the implant is covered with a mixture of two powders: binding and structural. Both powders bind to the implant surface, but only the structural one does so in a durable way. Binding powder is supposed to only block potential binding places for structural powder, stochastically. After that, it is removed, whereas remaining structural powder that is bound to the surface creates processes making the surface rougher. Such modified zirconium implants are being thoroughly studied in cell and animal models.

\section{References}

1. Tylman SD. History of crown and bridge prosthodontics. Theory and practice of crown and bridge prosthodontics. $1^{\text {st }}$ ed. St. Louis: The CV Mosby Co;1965:15-47.

2. Spiechowicz E. Protetyka Stomatologiczna. $6^{\text {th }}$ ed. Warszawa: PZWL; 2008:132-135.

3. Ring ME. Dentistry, an illustrated history. New York: HN Abrams; 1985:160-181.

4. Driskell TD. History of implants. CDA J. 1987;15:16-25.

5. Strock EA. Experimental work on a method for the replacement of missing teeth by direct implantation of a metal support into the alveolus. Am J Orthodont Oral Surg. 1939;25:457-472.

6. Piconi C, Maccauro G. Zirconia as a ceramic biomaterial. Biomaterials. 1999;20:1-25.

7. Fanghanel J, Gedrange T, Proff P. Bone quality, quantity and metabolism in terms of dental implantation. Biomed Eng. 2008;53:215-219.

8. Shulte W. The intra-osseous Al2O3 (Frialit) Tuebingen Implant. Developmental status after eight years. Quintessence Int. 1984; 15:1-39.

9. De Wijs FL, Van Dongen RC, De Lange GL, De Putter C. Front tooth replacement with Tubingen (Firalit) implant. J Oral Rehabil. 1994:21:11-26.

10. Schulte W, d'Hoedt B. Jahre Tubinger Implantat aus Frialit-Weitere Ergebnisse. Zeitsch Zahnarzt Implant. 1988;3:167-172.

11. Kohal RJ, Att W, Bachle M, Butz F. Ceramic abutments and ceramic oral implants. An update. Periodontol 2000. 2008;47:224-243.

12. Pirker W, Kocher A. Immediate, non-submerged, root-analogue zirconia implant in single tooth replacement. J Oral Maxillofac Surg. 2008;37:293-295.

13. Kohal RJ, Klaus G, Strub JR. Zirconia-implant-supported all-ceramic crowns withstand long-term load: A pilot investigation. Clin Oral Implants Res. 2006;17:565-571.

14. Silva NR, Coelho PG, Fernandes CA, Navarro JM, Dias RA, Thompson VP. Reliability of one-piece ceramic implant. J Biomed Mater Res B Appl Biomater. 2009;88:419-426.

15. Hisbergues M, Vendeville S, Vendeville P. Zirconia. Established facts and perspectives for a biomaterial in dental implantology. J Biomed Mater Res B Appl Biomater. 2009;88:519-529.

16. Chevalier J. What future for zirconia as a biomaterial? Biomaterials. 2006;27:535-543.

17. Dion I, Rouais F, Baquey C, et al. Physico-chemistry and cytotoxicity of ceramics: Part I: Characterization of ceramic powders. J Mater Sci Mater Med. 1997;8:325-332.

18. Li J, Liu Y, Hermansson L, Soremark R. Evaluation of biocompatibility of various ceramic powders with human fibroblasts in vitro. Clin mater. 1993;12:197-201.

19. Ko HC, Han JS, Bachle M, Jang JH, Shin SW, Kim DJ. Initial osteoblast-like cell response to pure titanium and zirconia/alumina ceramics. Dent Mater. 2007;23:1349-1355.
20. Botzenhart U, Kunert-Keil C, Heinemann F, et al. Osseointegration of short titan implants: A pilot study in pigs. Ann Ana. 2015;199:16-22.

21. Leonhardt A, Grondahl K, Bergstrom C, Lekholm U. Long-term follow-up of osseointegrated titanium implants using clinical, radiographic and microbiological parameters. Clin Oral Implants Res. 2002;13:127-132.

22. Oshida Y. Requirements for successful biofunctional implants. In: The $2^{\text {nd }}$ Symposium International of Advanced Bio-Materials. Montreal, Canada 2000, 5-10.

23. Oshida Y, Hashem A, Nishihara T, Yapchulay MV. Fractal dimension analysis of mandibularbones:Toward a morphological compatibility of implants. Bio-medical materials and engineering. 1994;4:397-407.

24. Heinemann F, Bourauel C, Hasan I, Gedrange T. Influence of the implant cervical topography on the crestal bone resorption and immediate implant survival. J Physiol Pharmacol. 2009; 60(Suppl 8):99-105.

25. Allegrini S, Jr., Allegrini MR, Yoshimoto M. Soft tissue integration in the neck area of titanium implants - an animal trial. J Physiol Pharmacol. 2008;59(Suppl 5):117-132.

26. Matsuzaka K, Walboomers XF, Yoshinari M, Inoue T, Jansen JA. The attachment and growth behavior of osteoblast-like cells on microtextured surfaces. Biomaterials. 2003;24:2711-2719.

27. Zinger O, Anselme K, Denzer A, et al. Time-dependent morphology and adhesion of osteoblastic cells on titanium model surfaces featuring scale-resolved topography. Biomaterials. 2004;25:2695-2711.

28. Deligianni DD, Katsala N, Ladas S, Sotiropoulou D, Amedee J, Missirlis YF. Effect of surface roughness of the titanium alloy Ti-6Al-4V on human bone marrow cell response and on protein adsorption. Biomaterials. 2001;22:1241-1251.

29. de Oliveira PT, Nanci A. Nanotexturing of titanium-based surfaces upregulates expression of bone sialoprotein and osteopontin by cultured osteogenic cells. Biomaterials. 2004, 25, 403-413.

30. Anselme K, Bigerelle M. Topography effects of pure titanium substrates on human osteoblast long-term adhesion. Acta biomaterialia. 2005;1:211-222.

31. Hayashi K, Matsuguchi N, Uenoyama K, Sugioka Y. Re-evaluation of the biocompatibility of bioinert ceramics in vivo. Biomaterials. 1992;13:195-200.

32. Chang YS, Oka M, Nakamura T, Gu HO. Bone remodeling around implanted ceramics. J Biomed Mater Res. 1996;30:117-124.

33. Dubruille JH, Viguier E, Le Naour G, Dubruille MT, Auriol M, Le Charpentier Y. Evaluation of combinations of titanium, zirconia, and alumina implants with 2 bone fillers in the dog. Int J Oral Maxillofac Implants. 1999;14:271-277.

34. Stanic V, Aldini NN, Fini M, et al. Osteointegration of bioactive glass-coated zirconia in healthy bone: An in vivo evaluation. Biomaterials. 2002;23:3833-3841.

35. Scarano A, Di Carlo F, Quaranta M, Piattelli A. Bone response to zirconia ceramic implants: An experimental study in rabbits. J Oral Implantol. 2003;29:8-12.

36. Aldini NN, Fini M, Giavaresi G, et al. Osteointegration of bioactive glass-coated and uncoated zirconia in osteopenic bone: an in vivo experimental study. J Biomed Mater Res A. 2004;68:264-272.

37. Sennerby L, Dasmah A, Larsson B, Iverhed M. Bone tissue responses to surface-modified zirconia implants: A histomorphometric and removal torque study in the rabbit. Clin Implant Dent Relat Res. 2005;7(Suppl 1);S13-20.

38. Depprich R, Zipprich H, Ommerborn M, et al. Osseointegration of zirconia implants compared with titanium: An in vivo study. Head Face Med. 2008;4:30.

39. Kohal RJ, Weng D, Bachle M, Strub JR. Loaded custom-made zirconia and titanium implants show similar osseointegration: An animal experiment. J Periodontol. 2004;75:1262-1268.

40. Akagawa $Y$, Ichikawa $Y$, Nikai $H$, Tsuru $H$. Interface histology of unloaded and early loaded partially stabilized zirconia endosseous implant in initial bone healing. J Prosthet Dent. 1993;69:599-604. 